\title{
Biology of the Transmission of Peach Mosaic Virus by Eriophyes insidiosus (Acari: Eriophyidae)
}

Carmen Gispert, Department of Entomology, George N. Oldfield, Department of Plant Pathology, Thomas M. Perring, Department of Entomology, and Rebecca Creamer, Department of Plant Pathology, University of California, Riverside 92521

\begin{abstract}
Gispert, C., Oldfield, G. N., Perring, T. M., and Creamer, R. 1998. Biology of the transmission of peach mosaic virus by Eriophyes insidiosus (Acari: Eriophyidae). Plant Dis. 82:1371-1374.

Experiments were undertaken to elucidate the characteristics of the transmission of peach mosaic virus (PMV) by Eriophyes insidiosus. Transmission efficiency by single E. insidiosus was as high as $17 \%$. The minimum inoculation access period was between 3 and 6 h. E. insidiosus acquired the virus after a minimum acquisition access period of 3 days. No latent period was demonstrated. While most plant viruses which are transmitted by eriophyid mites are transmitted in a persistent mode, our data are more consistent with a semipersistent model.
\end{abstract}

Additional keywords: bud mite, Eriophyoidea

Peach mosaic, a disease of stone fruits first reported in 1932 in Texas (8), has been reported in the southwestern and southern United States. $(1,2,14)$. It was found recently in commercial peach (Prunus persica (L.) Batsch) varieties grown in northern Chihuahua, Mexico, and in criollo varieties of peach grown in the various states of central Mexico (16). The causal agent of the disease is peach mosaic virus (PMV), which has long, flexuous, rod-shaped particles. Although PMV has not been conclusively grouped (6), it is serologically related to cherry mottle leaf virus (5).

Symptoms of peach mosaic include mosaic on leaves in the spring and early summer, vein clearing, color break and deformation of petals, stunted leaves, fruit deformity, and dwarfing of the twigs (19). Symptoms are milder in criollo varieties than in other commercial peaches (16). Most freestone cultivars show strong symptoms, while clingstone cultivars express only mild symptoms (17). Peach mosaic virus also infects almonds (Prunus dulcis (Mill.) D.A. Webb), apricots (P. armeniaca L.), and plums ( $P$. americana Marsh.) (3).

Eriophyes insidiosus Keifer \& Wilson is the vector of PMV (20). The host range of

Corresponding author: C. Gispert

E-mail: gispert@ucrac1.ucr.edu

This research was partially supported by a fellowship from the CONACYT (National Council of Science and Technology, Mexico).

Accepted for publication 8 September 1998.

Publication no. D-1998-1022-02R

(C) 1998 The American Phytopathological Society
E. insidiosus includes many varieties of commercial and flowering peaches and wild Prunus sp. (19). The vector is found on commercial peach varieties, in growthretarded buds located on the base of the trunk or the lower part of scaffold branches, in densities of 500 to $900 \mathrm{E}$. insidiosus per bud (14). On criollo varieties, high densities of E. insidiosus develop in buds distributed along the trunk and branches (16).

E. insidiosus survives only within vegetative buds, where it feeds and reproduces between closely adhering bud scales. Infested buds of commercial peaches usually possess loosened scales and a swollen appearance as a result of mite feeding (20). Once established in a bud, mites can develop high densities within 2 months (7). Thus, a tree with a single infested bud may yield hundreds of mites.

Wind is the probable means of mite dispersal (12). When infested buds dry, mites migrate to new buds, even though the mortality of mites is probably high. Despite this, epidemics of peach mosaic can progress at a rapid rate. Jones and Wilson (11) found that 23 and 167 trees became infected with PMV over a 1-year period when 390 and 445 trees, respectively, were evaluated.

Little is known about transmission of PMV by E. insidiosus. When viruliferous adults were transferred singly to 80 healthy peach seedlings used as test plants, two plants $(2.5 \%)$ became infected. When 2 to 10 viruliferous mites were transferred per test plant, 11 of 56 plants $(20 \%)$ were infected, and when over 50 mites were transferred per test plant, 18 of 25 plants $(72 \%)$ became infected (14).

When 5,400 E. insidiosus eggs were transferred from PMV-infected plants to 28 healthy peach seedlings, no plants developed symptoms (14). The absence of symptoms was interpreted as evidence that PMV was not transovarially transmitted. Other details of the transmission process are unresolved because of the difficulty in rearing (7) and manipulating E. insidiosus.

In this paper, the parameters of PMV transmission by E. insidiosus are presented.

\section{MATERIALS AND METHODS}

Maintenance of indicator plants. 'Rio Oso Gem' (ROG) peach seedlings were used as indicator plants in all transmission tests because they show severe symptoms in response to PMV infection. Fruit of ROG were obtained from Dowling Fruit (Beaumont, CA). Fruit flesh was removed, and the endocarps were cleaned and stored at $4^{\circ} \mathrm{C}$.

Peach endocarps were cracked to remove the seed. Seeds were washed with $1 \%$ Joy liquid detergent, rinsed with tap water, surface sterilized for 3 min with $0.52 \%$ sodium hypochlorite, and rinsed 3 times for $30 \mathrm{sec}$ with sterile water. The seeds then were placed in plastic storage bags containing a folded paper towel drenched with $10 \mathrm{ml}$ of Captan solution $(0.5 \mathrm{~g} / \mathrm{l})$ to preclude fungal growth. These seeds were stratified for 12 to 16 weeks in the dark at $4^{\circ} \mathrm{C}$. In preparation for infestation by mites, germinated peach seeds were transplanted into 5-cm plastic pots. After infestation, seedlings were replanted in 10$\mathrm{cm}$ cardboard pots and transferred to a greenhouse for 6 weeks for development of symptoms. After 6 weeks, asymptomatic plants were further stratified for 10 weeks and observed for symptom expression 6 weeks after dormancy ended.

E. insidiosus were transferred using a single human eyelash mounted to a wooden probe $15 \mathrm{~cm}$ long by $2 \mathrm{~mm}$ in diameter. Dissecting microscopes were used to observe the collection of mites from infested buds and the transfer of mites to buds of tests plants.

Serological analysis. Transmission of PMV resulted in symptomatic leaves and was corroborated by Western blot analysis using a monoclonal antibody probe to cherry mottle leaf virus (9) which was previously found to detect PMV (5). Samples for serological analysis were prepared by grinding $0.25 \mathrm{~g}$ leaf tissue in liquid nitrogen followed by the addition of $1.5 \mathrm{ml}$ Laemmli buffer (13). Samples were boiled 
for $5 \mathrm{~min}$, centrifuged at $15,000 \mathrm{rpm}$ for 3 min, and the supernatant decanted to a new tube. Proteins were separated by electrophoresis in a $15 \%$ gel by sodium dodecyl sulfate-polyacrylamide gel electrophoresis in a mini-gel apparatus (Bio-Rad Laboratoblotted to Immobilon-P membranes (Millipore, Bedford, MA) and the membranes were blocked with $5 \%$ nonfat dry milk in TM buffer (0.05M Tris, $0.01 \mathrm{~m} \mathrm{MgSO}_{4}, \mathrm{pH}$ 8.5) for $1 \mathrm{~h}$. Monoclonal antibody probes and alkaline phosphatase-conjugated rabbitanti-mouse immunoglobulins ( $\operatorname{IgG}$ ) were used at 1:2000 vol/vol dilution in TM buffer. Nitrobluetetrazolium (NBT) and 5bromo-4chloro-3-indoyl- $\beta$-D-galactoside (BCIP) were added for color development.

Transmission tests. Mites were obtained from three naturally infected ornamental flowering peach trees growing in Chino, California (Chino source; 16), or one ornamental flowering nectarine tree (Prunus persica var. nectarina Aiton; nectarine source) growing near the campus of the University of California, Riverside. PMV infection in the nectarine source was identified by symptoms and verified by Western blot analyses. Infested-buds collected for experiments were maintained in plastic bags at $4^{\circ} \mathrm{C}$. Healthy ROG seedlings used as indicator plants were kept in the greenhouse to detect eriophyid contamination. A Diazinon solution (0.366 $\mathrm{ml} / 100 \mathrm{ml}$ water) was used to kill experimental mites. Preliminary tests showed that this concentration of Diazinon stopped mite feeding immediately after insecticide application and killed E. insidiosus within 5 min. Plants to which mites were transferred were held in the laboratory for 1 day, then placed in the greenhouse for 6 weeks and observed for symptoms, then tested for PMV by Western blot analyses.

Transmission efficiency. Viruliferous E. insidiosus were obtained from the Chino source trees. PMV infection in the source trees was confirmed by Western blot analyses. Transmission experiments were conducted using buds from these trees. In a preliminary experiment, mites were transferred individually from two infested buds to 90 indicator seedlings in 2 days. Transfers of 3, 5, and 10 mites per seedling were conducted in three experiments. One miteinfested bud was used in each experiment. In the first experiment, mites were transries, Richmond, CA). Gel proteins were

ferred the day they were collected. In the second and third experiments, mite-infested buds used were stored in a plastic bag at $4^{\circ} \mathrm{C}$ for 2 and 3 days, respectively. The number of test seedlings used for each treatment is indicated in Table 1. Indicator test plants infested by mites were held in the laboratory for 1 day, then placed in the greenhouse and observed for symptoms for 2 months, after which they were tested for PMV by Western blot analysis. Mites transferred in these experiments were not killed. Several control non-infested ROG plants were placed in the greenhouse to detect contamination.

Inoculation access period. Naturally viruliferous $E$. insidiosus were obtained from the nectarine source. Inoculativity of the mites was verified by a preliminary experiment in which ROG peach plants developed symptoms after mite transfer and PMV was detected by Western blot analysis. From the same bud, adult mites were transferred in groups of 10 to newly developed leaves of 7- to-10-day-old peach seedlings. Two experiments were conducted to compare $15 \mathrm{~min}, 30 \mathrm{~min}, 3 \mathrm{~h}, 6$ $\mathrm{h}$, or $12 \mathrm{~h}$ inoculation access periods (IAP; Table 2). Infested buds used were stored at $4^{\circ} \mathrm{C}$ for 0 to 5 days in the first experiment and 6 to 11 days in the second experiment. Feeding of mites was terminated by dipping the seedlings in a solution of Diazinon $(0.366 \mathrm{ml} / 100 \mathrm{ml}$ water; 10$)$. Plants were then transferred to the greenhouse and observed for symptom development for 2 months, after which they were tested for PMV by Western blot analysis.

Acquisition access period. For the acquisition access period (AAP) and latent period (LP) determinations, virus-free mites were collected from two naturally mite-infested but PMV-free flowering peach trees located at the University of California, Riverside. These trees were monitored annually for PMV infection using two methods. In the first, pieces of bark were grafted from the 2 trees to 10 healthy 1-year-old peach trees, which were subsequently evaluated for infection by symptomatology for 3 years. In each of the 2 subsequent years, five trees were grafted. All the trees were held for symptom observation for 3 years. For the second method, 10 adult mites from each tree were transferred annually to each of 10 indicator plants. Indicator peach seedlings in both

Table 1. Transmission efficiency of peach mosaic virus (PMV) by Eriophyes insidiosus (EI) ${ }^{\mathrm{a}}$

\begin{tabular}{|c|c|c|c|}
\hline \multirow[b]{2}{*}{ \# EI/plant } & \multicolumn{3}{|c|}{ Plants infected/plants tested (\% transmission) ${ }^{\mathbf{b}}$} \\
\hline & Exp. 1 & Exp. 2 & Exp. 3 \\
\hline 3 & $2 / 4(50)$ & $0 / 4(0)$ & $0 / 4(0)$ \\
\hline 5 & $0 / 4(0)$ & $0 / 4(0)$ & $0 / 4(0)$ \\
\hline 10 & $0 / 4(0)$ & $0 / 4(0)$ & $1 / 4(25)$ \\
\hline
\end{tabular}

a 'Rio Oso Gem' peach seedlings were infested with viruliferous $E$. insidiosus and rated for symptoms 14 days postinoculation.

${ }^{\mathrm{b}}$ Infection with PMV was determined by visual symptoms on trees and corroborated by Western blot analysis. methods did not develop symptoms in the 3-year testing period.

Peach trees used as virus-infected sources were produced by exposing ROG peach trees to mites obtained from the Chino or nectarine source, or by grafting trees with Chino source buds. A total of 28 1- to 6-year-old infected trees were used as the source plants for the AAP and LP experiments.

New buds were induced on healthy and infected trees by manually removing the leaves when trees ceased growth (indicated by the absence of new leaves on the tip of the branches). The trees then were held at $4^{\circ} \mathrm{C}$ for 6 to 8 weeks for stratification, after which trees were moved to a greenhouse. Buds began developing 5 to 7 days afterward, and buds of the appropriate stage to use in the experiments developed in 10 to 15 days. Buds located at the base of the trunk were selected because observations indicated that these basal buds developed more slowly than buds on the branches, and produced less of a polysaccharide secretion which often entangled mites. After approximately 1 month, trees stopped developing buds, but stems continued to grow for the next 4 to 6 months. When these stems ceased growing, leaves were removed, and the trees were stored at $4^{\circ} \mathrm{C}$ for stratification.

To determine the AAP, approximately 100 adult mites were transferred from 1 or more healthy buds to each of 35 buds on 12 PMV-infected peach trees. Transfer of 100 mites to a single bud was accomplished in $1 \mathrm{~h}$. These transfers were done in two experiments. In the first experiment, 25 peach buds were infested with approximately 2,500 adult and 500 immature mites; in the second experiment, 10 buds were infested with approximately 1,200 adult and 130 immature mites. Adult and immature E. insidiosus were distinguished by size and body color. Adults were larger and yellowish, in comparison with immature mites, which were smaller, with an almost translucent body. After access for 1, 2,3 , or 5 days, surviving mites were trans-

Table 2. Transmission of peach mosaic virus by adult Eriophyes insidiosus after different inoculum storage times ${ }^{\mathrm{a}}$

\begin{tabular}{|c|c|c|}
\hline \multirow[b]{2}{*}{$\mathbf{I A P} \mathbf{P}^{\mathbf{c}}$} & \multicolumn{2}{|c|}{ Cold stored bud ${ }^{b}$} \\
\hline & 0-5 days & 6-11 days \\
\hline $15 \mathrm{~min}$ & $0 / 5 \quad(0)$ & $0 / 8 \quad(0)$ \\
\hline $30 \mathrm{~min}$ & $0 / 17(0)$ & Not tested \\
\hline $3 \mathrm{~h}$ & $0 / 1 \quad(0)$ & $0 / 4 \quad(0)$ \\
\hline $6 \mathrm{~h}$ & $3 / 5(60)$ & $3 / 5(60)$ \\
\hline $12 \mathrm{~h}$ & $2 / 5(40)$ & $3 / 5(60)$ \\
\hline
\end{tabular}

a 'Rio Oso Gem' peach seedlings were each infested with 10 viruliferous $E$. insidiosus. Infection with peach mosaic virus was determined by visual symptoms on trees and corroborated by Western blot analysis.

${ }^{b}$ Ratio shows plants infected/plants tested (percentage of transmission).

c IAP = inoculation access period. 
ferred (in groups of 5 to 10) to 56 test plants in the first experiment and to 37 in the second experiment (Table 3) and allowed to feed for $24 \mathrm{~h}$, after which they were killed by dipping the plants in a solution of Diazinon $(0.366 \mathrm{ml} / 100 \mathrm{ml}$ water$)$. After insecticide treatment, peach seedlings were placed in the greenhouse and observed over a period of 6 weeks for development of symptoms, after which they were tested for PMV with Western blot analysis.

Possible latent period. Based on the results of the AAP study (i.e., transmission with 5-day AAP), a series of experiments were conducted to determine how much of the 5-day period was required for acquisition and how much, if any, was required for a latent period. To address this question, potential latent periods, equal to the time to complete 5 days, after AAPs of $6 \mathrm{~h}$, $12 \mathrm{~h}, 1$ day, 2 days, and 5 days, were tested. Over 10,000 adult mites, in groups of 100 , were given access to 85 buds infected with Chino source PMV, and adult survivors were transferred after the specific AAPs to healthy ROG peach buds on intermediate plants to complete latent periods of 4.75 days, 4.5 days, 4 days, and 3 days, respectively. When each latent period was completed, groups of 5 to 10 mites were transferred to 71 test seedlings and allowed to feed for 1 day. Control mites with 5-day AAPs were transferred to test plants without a latent period. The seedlings were observed for 6 weeks in the greenhouse to assess symptomatology and were tested for PMV by Western blot analyses.

\section{RESULTS}

Transmission efficiency. Non-viruliferous control E. insidiosus never transmitted PMV, and non-infested control ROG plants never developed PMV symptoms. In the initial experiment, when individual mites were transferred, 16 of 90 test plants (17\%) developed mosaic symptoms after exposure to single mites. When 3 mites per plant were tested, 2 of 12 plants (16\%) showed symptoms; when 5 mites per plant were transferred, no transmission occurred;

Table 3. Transmission by Eriophyes insidiosus of peach mosaic virus after various acquisition access periods (AAP) in days and 1-day inoculation access period (IAP) ${ }^{\mathrm{a}}$

\begin{tabular}{|c|c|c|}
\hline \multirow{2}{*}{$\begin{array}{l}\text { AAP } \\
\text { (days) }\end{array}$} & \multicolumn{2}{|c|}{$\begin{array}{c}\text { Plants infected/plants tested } \\
\text { (\% transmission) }\end{array}$} \\
\hline & Exp. 1 & Exp. 2 \\
\hline 1 & $0 / 9 \quad(0)$ & $0 / 15(0)$ \\
\hline 2 & $0 / 15 \quad(0)$ & $0 / 2 \quad(0)$ \\
\hline 3 & $2 / 15(13)$ & $0 / 15(0)$ \\
\hline 5 & $5 / 17$ (29) & $4 / 5(80)$ \\
\hline
\end{tabular}

${ }^{a}$ Between 5 and 10 E. insidiosus/plant were placed onto 'Rio Oso Gem' peach seedlings. Infection with peach mosaic virus was determined by visual symptoms on trees and corroborated by Western blot analysis. and when 10 mites per plant were used, 1 of 12 plants $(8 \%)$ developed mosaic symptoms (Table 1). Transmission (and virus symptoms) of PMV were verified by Western blot analyses.

Inoculation access period. None of the 35 plants exposed to E. insidiosus for IAPs of $3 \mathrm{~h}$ or less became infected (Table 2). However, $60 \%$ of the plants exposed to $E$. insidiosus for $6 \mathrm{~h}$ from buds held at $4^{\circ} \mathrm{C}$ up to 11 days developed symptoms of peach mosaic 10 to 15 days after exposure. Thus, adult mites did not lose inoculativity under these time and temperature conditions. In all cases, symptomatic plants were positive for PMV infection by Western blot analysis.

Acquisition access period. Virus-free E. insidiosus acquired PMV and transmitted it to 2 of 30 test plants $(6 \%)$ after a 3day AAP and to 9 of 22 healthy peach seedlings $(40 \%)$ after a 5-day AAP (Table 3). In the 3-day AAP test, 13 infected buds were used as virus sources, but successful transmission resulted from only 2 of these 13 infected buds. In the 5-day AAP test, seven buds were used as virus sources and positive transmissions occurred from four buds. Observations showed that E. insidiosus were alive $24 \mathrm{~h}$ after the second transfer.

Possible latent period. Peach trees used to hold the E. insidiosus between AAP and IAP never showed symptoms of PMV. After these intermediate period transfers were completed, none of the 71 test plants became infected and only control mites transmitted PMV after 5 days AAP (Table 4).

\section{DISCUSSION}

To determine the relationships between E. insidiosus and peach mosaic virus, transmission efficiency, inoculation access period, acquisition access period, and latent period were studied.

In the first transmission efficiency trial, the higher efficiency found for single individuals $(17 \%)$ compared to lower efficiencies for 3, 5, or 10 E. insidiosus may have been a result of the E. insidiosus popula-

Table 4. Possible latent period of peach mosaic virus by Eriophyes insidiosus after various acquisition access periods (AAP) and time on intermediate transfer host ${ }^{\mathrm{a}}$

\begin{tabular}{lcc}
\hline AAP & $\begin{array}{c}\text { Duration on } \\
\text { intermediate } \\
\text { host }\end{array}$ & $\begin{array}{c}\text { Plants } \\
\text { infected/plants } \\
\text { tested }\end{array}$ \\
\hline $6 \mathrm{~h}$ & 4.75 days & $0 / 20$ \\
$12 \mathrm{~h}$ & 4.5 days & $0 / 14$ \\
1 day & 4 days & $0 / 20$ \\
2 days & 3 days & $0 / 17$ \\
5 days & 0 days & $4 / 5$ \\
\hline
\end{tabular}

${ }^{\text {a }}$ Possible latent period $=$ acquisition access period + time on intermediate host + 1-day inoculation access period. Results are a compilation of a series of experiments. Infection with peach mosaic virus was determined by visual symptoms on trees and corroborated by Western blot analysis. tions from which test E. insidiosus were selected. Single E. insidiosus were collected from buds with adults constituting a large proportion of the population. Young populations of E. insidiosus, represented by a high proportions of immature and young adult mites, were present in the buds which had been colonized recently. This suggests that the E. insidiosus used for single transmissions likely had longer exposure to the infected tissue than those transferred in groups of 5 or $10 \mathrm{E}$. insidiosus, which may not have had access to infected tissue long enough to become viruliferous. Additionally, E. insidiosus were selected from more than one bud, possibly introducing variability into the study, and resulting in E. insidiosus from the various buds being differentially viruliferous.

Greater transmission rates from single $E$. insidiosus transfers also could have been related to availability of PMV in the buds from which $E$. insidiosus were selected. The specific distribution and variation in titer within the source trees infected with PMV are not known, but PMV has been reported in roots, stems, leaves, flowers, and fruit parts except seeds (4). Trees from which buds were removed for the experiments showed mosaic, vein clearing, deformation, or necrotic areas in most of the leaves, indicating a systemic distribution of the virus within the tree. Another variable, which could have influenced the results of these experiments, was the amount of time infested buds were stored at cool temperatures prior to their use, thereby reducing $E$. insidiosus feeding. However, the successful transmission by E. insidiosus held for 11 days in the IAP test suggests that cold storage did not influence transmission.

Results from these trials contrast with previous data (14), which showed that transmission rate increased proportionally with higher numbers of $E$. insidiosus transferred. Unfortunately, in the previous study, the origins of $E$. insidiosus used for specific tests were not recorded, and may have affected the demonstrated efficiency rates with different numbers of $E$. insidiosus.

The ability of E. insidiosus to reach high densities in a short time, fastidious host requirements which contribute to high mortality during migration, and transmission efficiency influence PMV epidemics in the field. A single bud can harbor large numbers of mites, but only a small percentage of them may be efficient vectors. Alternatively, when mites have been exposed to infected tissue long enough to become viruliferous, transmission efficiency may be high. Vector efficiency may also be related to life stage, such that adults are more efficient than immature mites because the latter may lose inoculativity when molting.

E. insidiosus transmitted PMV with a 6$\mathrm{h}$ IAP, but required 3 days to acquire the virus, suggesting the possibility that a la- 
tent period existed. Mites did not transmit the virus after a 2-day AAP (48 h) in the latent period experiment (Table 4), but did transmit the virus after a 3-day AAP (72 h) in the AAP experiment (Table 3). In the IAP experiment, $E$. insidiosus transmitted the virus after a minimum of $6 \mathrm{~h}$.

There is a single report in the literature of a suspected latent period in an eriophyidvirus system. Proeseler (18) reported that Aceria ficus (Cotte), the vector of fig mosaic virus, did not transmit during the first 6 to 7 h IAP after AAPs of $5 \mathrm{~min}, 1$ to $2 \mathrm{~h}$, or 4 to $5 \mathrm{~h}$, but they transmitted within minutes after $24 \mathrm{~h}$ of access to infected tissue. This reported delay in the ability to transmit constitutes the only reported evidence of a latent period being involved in the transmission of plant viruses by mites (15).

The absence of transmission in the latent period experiment suggested that $E$. insidiosus required long acquisition times without a latent period to become viruliferous. If true, the long acquisition access might be dose-dependent. E. insidiosus may acquire virus in short AAPs, but are not able to transmit until they ingest a minimum virus concentration.

The common mode of transmission among the Eriophyoidea is thought to be a persistent mode (15). However, data from previous work (14) and from this study show that E. insidiosus does not transmit $\mathrm{PMV}$ in this manner. Peach mosaic virus was transmitted after a 6-h IAP and a 3-day AAP, but transmission increased with a 5day AAP. These results point to a semiper- sistent mode, in which vectors do not acquire virus during brief AAPs. Among other characteristics, adult E. insidiosus retain the virus for 2 days, and there is no evidence of transovarial transmission or latent period (14), which are consistent with the transmission characteristics of other viruses transmitted in a semipersistent manner.

\section{ACKNOWLEDGMENTS}

We thank D. James, Agriculture Canada, Plant Quarantine Station, Saanichton, British Columbia, for the generous supply of monoclonal antibody for cherry mottle leaf.

\section{LITERATURE CITED}

1. Bodine, E. W. 1934. Occurrence of peach mosaic in Colorado. Plant Dis. Rep. 18:123.

2. Bodine, E. W. 1936. Peach mosaic disease in Colorado. Colorado Exp. Stn. Bull. 421.

3. Cochran, L. C. 1940. Relation of peach mosaic disease to other mosaics of stone fruits. Calif. Cultivator 87:164-165.

4. Cochran, L. C., and Rue, J. L. 1944. Some host-tissue relationships of the peach mosaic virus. (Abstr.) Phytopathology 34:934.

5. Creamer, R., Gispert, C., and Oldfield, G. N. 1994. Partial characterization of peach mosaic virus. Pages 21-23 in: Rose Rossette Symp. A. Epstein and J. Hill, eds. Iowa State University, Ames.

6. Gispert, C., Perring, T. M., and Creamer, R. 1998. Purification and characterization of peach mosaic virus. Plant Dis. 82:905-908.

7. Gispert, C., Perring, T. M., and Oldfield, G. N. 1997. Rearing Eriophyes insidiosus Keifer and Wilson (Acari: Eriophyidae), a fastidious bud mite. Int. J. Acarol. 23:1-4.

8. Hutchins, L. M. 1932. Peach mosaic. A new disease. Science 76:123.

9. James, D., and Mukerji, S. 1993. Mechanical transmission, identification, and characteriza- tion of a virus associated with mottle leaf in cherry. Plant Dis. 77:271-275.

10. Jones, L. S., Wilson, N. S., Burr, W., and Barnes, M. W. 1970. Restriction of peach mosaic virus spread through control of the vector Eriophyes insidiosus. J. Econ. Entomol. 63:1551-1552.

11. Jones, L. S., and Wilson, S. W. 1951. Peach mosaic spreads throughout growing season. Calif. Dep. Agric. Bull. 3:117-118.

12. Keifer, H. H. 1975. Eriophyoidea Nalepa. Pages 327-396 in: Mites Injurious to Economic Plants. L. R. Jeppson, H. H. Keifer, and E. W. Baker, eds. University of California Press, Berkeley.

13. Laemmli, U. K. 1970. Cleavage of structural proteins during assembly of the head of bacteriophage T4. Nature 227:680-683.

14. Oldfield, G. N. 1970. Mite transmission of plant viruses. Annu. Rev. Entomol. 15:343380.

15. Oldfield, G. N. 1994. Eriophyid mite as vectors of plant disease agents. Pages 11-16 in: Proc. Rose Rossette Symp. A. Epstein and J. Hill, eds. Iowa State University, Ames.

16. Oldfield, G. N., Creamer, R., Gispert, C., Osorio, F., Rodriguez, R., and Perring, T. M. 1995. Incidence and distribution of peach mosaic and its vector Eriophyes insidiosus (Acari: Eriophyidae) in Mexico. Plant Dis. 79:186-189.

17. Pine, T. S. 1976. Peach mosaic. Pages $61-72$ in: Virus Diseases and Noninfectious Disorders of Stone Fruits in North America. U. S. Dep. Agric. Handb. No. 437

18. Proeseler, G. 1972. Relationships between virus, vector, and host plant shown by fig mosaic virus and Aceria ficus (Cotte). Acta Phytopathol. Acad. Sci. Hung. 7:179-186.

19. Stout, G. L. 1939. Peach Mosaic. Calif. Dep. Agric. Bull. 28:177-200.

20. Wilson, N. S., Jones, L S, and Cochran, L.C. 1955. An eriophyid mite vector of the peach mosaic virus. Plant Dis. Rep. 39:889-892. 